\title{
On Interdisciplinary Comparative Study of Analogical Feedback/Assessment Models Applied in Blended Learning Versus Computer Aided Learning using Artificial Neural Networks
}

\author{
Hassan M. H. Mustafa \\ Staff Mem./Dept. of Ed Tech \\ Faculty of Specified Ed., \\ Banha University, Egypt
}

\author{
Hany S. Ramzy \\ Staff Mem./Dept. of Ed Tech \\ Faculty of Specified Ed., \\ Banha University, Egypt
}

\author{
Satish Gajawada \\ Alumnus, Indian Institute of \\ Technology Roorkee \\ Founder, Artificial Human \\ Optimization Field
}

\begin{abstract}
This paper provides educationalists as well as researchers in computer science and engineering with a study of an interdisciplinary challenging pedagogical issue. More specifically, that presented study resulting in a set of interesting findings originated from adopted realistic Artificial Neural Network's $\left(\mathrm{ANN}^{\mathrm{s}}\right)$ modeling, which associated to two educational analogical feedback / assessment processes. This piece of research considers comparative analysis and evaluation study of an educational phenomenon issue for two diverse teaching/learning methodologies namely:\{Blended Learning (BL), and Computer Aided Learning (CAL)\}. More precisely, introduced issue of this work addresses the two summative and formative assessment processes applied in educational field practice. Accordingly, this issue concerned mainly with modeling of two practical field case studies considering the two items of educational feedback/assessment. In other words, assessment is used in many ways in education, a great deal of attention is now given to its use in helping teaching and learning, described as the two performance assessment items (summative and formative). These both are classified as: assessment for learning ( $A f L$ ), or formative assessment. and assessment of learning $(A O L)$, or summative assessment. It is noticed that (A $f L$ ), did predict a substantial amount of course outcome and its validity observed to pave the way for diagnostic use and remedial teaching. However, $(A O L)$ is focused on summarizing what students know or can do at certain times in order to report their academic progress, and achievement. Herein, two parametric factor values of ANN (gain, and learning rate factors), have been considered for the two suggested instructional methodologies. That is considered in order to compare, analyze, and evaluate dynamically two items of academic performance namely: (Academic achievement outcome \& Learning convergence time) for both methodologies. Interestingly, after running of realistic ANN computer modeling for different numbers of neurons -that are contributing to learning process- results in a investigative, comprehensive, and innovative systematic analysis of individual students' differences. Finally, after performing perceptive evaluation comparing between two case studies of obtained experimental field results, two interesting findings have been concluded. Firstly, while comparing computed sets of statistical parameters, associated to the presented instructional methodologies $(B L \& C A L)$. that resulted in the observed analogy between both sets. Secondly, in the context of Feedback/Assessment performance, regarding both $(B L \&$
\end{abstract}

CAL) ; either Formative, or Summative feedback /assessments, have been observed to be well analogous to each other.

\author{
Keywords \\ Blended learning; Brain based learning; Computer Aided \\ Learning; Neural Networks Modeling; Formative, and \\ summative feedback /assessments.
}

\section{INTRODUCTION}

The field of learning sciences is represented by a growing community conceiving knowledge associated with educational system performance as well as assessment of technology-mediated learning (TML) processes. These processes consider learning environment in which learning and teaching. materials such as bidirectional interactive assignments between learners and instructors via advanced information technologies [1]. Therefore, Technology can be used to improve teaching and learning and help our students be successful. However, technology can be a "force multiplier" for the teacher. Instead of the teacher being the only source of help in a classroom, students can access web sites, online tutorials, and more to assist them. So, a set of evolutionary instructional trends have been adopted by educationalists besides their learners due to rapid technological and social changes [2][3]. In more details, by referring to [2], influences of information technology on mathematical education have been illustrated. Therein, a suggested approach for leading to build a better integration of information technology to teach and learn mathematics; and to point out some problems that emerge when the use of software is intense in such integration. Moreover, referring to [3], the Technology Integration Planning Model (TIP Model) shows teachers how to create an environment in which technology can effectively enhance learning. Furthermore, these teachers have been able to see in more depth their role in shaping the $\mathrm{f}$ educational technology in future. More precisely, that great innovative education means employing technologies aiming to fulfill the vision they make possible: a worldwide social network and a global community that learns and grows together. Therefore, they are facing increasingly challenges arise in this time considering modifications of various educational field applications [4][5][6]. It is good to remember what some authors say: "Computers are transforming the way mathematicians discover, prove and communicate ideas" (Horgan, 93)[7]. "Computers and computation have changed the entire modern world, but their effects in the fields of sciences and engineering have been especially deep" (Aragón, 96).[8]. it is more instructive to examine the potential of technology for changing the 
relationships between mathematicians and engineers, and for connecting their respective bridging between mathematics and engineering knowledge domains in new ways [9]. More specifically, in the context of teaching, and learning a selected mathematical topic titled: Long Division process [10][11]. That topic has been applied at classroom regarding two diversified multisensory models of Computer Aided Learning (CAL), given at [5][12][13][14]. Recently, by referring to the paper published online on: 8/29/2018 for, furthering educational methodology, it could be asked the challenging question: (Can you imagine modern education without computer software or the internet?). Whether you're taking a class online, researching for a paper or sharing work via the cloud, computer science pros have helped make this possible. E-learning platforms and applications give students new tools to problem-solve and study, which has changed the academic world [15] The ability to take classes online is also a huge benefit for the world-as it creates access to education for students whose locations, abilities or finances were a barrier [16]. Moreover, It is announced that: "Online education can provide mid-career training without forcing individuals to quit their jobs or move to locations with appropriate educational institutions." [17]. Recently, some innovative developed methodologies of instructional technology have been adopted and introduced for practical application in the educational field such as Virtual reality(VR), Massively Open Online Courses (MOOCs), and Blended Learning (BL). VR, is also being explored as a tool to increase immersive learning .According to Erica Orange, member of Devry University's Career Advisory Board, "The next generation of MOOCs will be sensorial immersive, leveraging virtual reality to put students in the world they're studying." [18] There are many examples of corporate research being done into this subject. An interesting research work concerned with MOOCs is presented under the question title". "What according to you is the future of MOOCs?"[19]. Therein, declared that The future of MOOCs is the future of education itself. The World of Comenius project employed a Leap Motion controller and specially adapted Oculus Rift DK2 headsets to teach biology at a school in the Czech Republic in 2016 (Sharma, 2016)[20]. Google launched Pioneer Expeditions in September 2015, where classrooms can access a library of hundreds of virtual "trips" (Moynihan, 2016)[21]. Virtual reality platforms such as Altspace VR and Lecture VR allow students to make avatars in order to collaborate with other players (Reede, 2016) [22] In fall 2015, Harvard began streaming its most popular class, CS50, in virtual reality on edX (Fahs, 2016) [23]. As teaching and learning today are not limited to the walls of the classroom and most universities and schools provide learning opportunities for their students through online and blended learning environments, assessment practices also gain much more importance (Stein \& Graham, 2014) [24].Within the recent 10 years the introduction of the new technological innovations such as Blended Learning (BL) filled the gap between traditional face-to-face learning and distributed learning environments. Regarding extended deep analysis of (BL) literature, it is stated that BL would have a great role in the future and it would be dominated by the distributed learning environments [25]. In 2017, Jennifer Hofmann made the argument that Blended Learning represents a true shift in the profession. Since then, BL has cemented itself as so much more than a passing fad. But now that blended learning is here to stay, how do we prove its value to our organizations? [26] Accordingly, the expansion of online and blended learning environments allows students to enjoy a potentially better teaching and learning experience. It is, therefore, vital that researchers as well as teachers that have online and blended learning classes adopt appropriate assessment. [27]. Recent literature review of $\mathrm{BL}$ research area in addition to suggesting key implications for tutor development, student retention and student progression have been introduced at [28]. More recently, Claire Johnson stated that:"The idea of blended learning arose as a flexible and easy way to incorporate technology into any classroom without adding too much to the already packed curriculums"[29]. Furthermore, this research work argues for standardizing early intervention via feedback to allow students to access specialist support where necessary, so as to address difficulties earlier in the course of studies so as to allow more students to reach their academic potential. Accordingly, in order to develop advanced skills of students in critical thinking and analysis congruent with degree-level qualifications, meaningful feedback and 'feed-forward' must be offered in order to facilitate such improvement. Research findings were encouraging. A statistical model incorporating feed-forward was developed which accounted for a large effect in the improvement of results for the summative item. Importantly, there was improvement across student ability levels. [30]. In the context of learning and feedback in Artificial Neural Networks ANN [31]., the back propagation algorithm, in combination with a supervised error-correction learning rule, is one of the most popular and robust tools in the training of ANN. Back propagation passes error signals backwards through the network during training to update the weights of the network [32]. Error-Correction Learning, used with supervised learning, is the ANN technique of comparing the system output to the desired output value, and using that error to direct the training. In the most direct route, the error values can be used to directly adjust the tap weights, using an algorithm such as the back-propagation algorithm. If the system output is $\boldsymbol{y}$, and the desired system output is known to be $\boldsymbol{d}$, the error signal can be defined as :

$(\boldsymbol{e}=\boldsymbol{d}-\boldsymbol{y})$. Error correction learning algorithms attempt to minimize this error signal at each training iteration. The most popular learning algorithm for use with error-correction learning is the back-propagation algorithm, discussed below [33]. Obviously, in the context of educational technology, the optimality of academic achievement (best learning outcome) for any instructional teaching/learning system could be attained (if and only if the value of error signal (e) approaches to have its value equals to zero). That obvious learning concept is deduced by details in below, and given by equation (8) based on synaptic connectivity as:\{ $\left.\Delta W_{\mathrm{kj}}(n)=0\right\}$. The rest of this paper is organized as follows.

At the next section, two folds of this research's motivation have been presented. Generalized model of interactive blended learning is introduced at the third section. At the fourth section simulation results are presented. Finally, some conclusive comments are given at the end of this paper.

\section{RESEARCH MOTIVATIONS}

This research work has investigated systematically via two motivations briefly given at the next two subsections as follow.

First Motivation: During the nineteenth of last century, technologies of computer, Information, and mobile devices play an essential role in how an individual's brain performs its working, living, playing, and, more importantly, learning. Accordingly, the decade (1990-2000) is called decade of the brain as announcement in 1989 WHITE HOUSE REPORT in U.S.A. [34]. Therefore, the overwhelming majority of neuroscientists have adopted the above brain concept which 
suggests that huge number of neurons in addition to their synaptic interconnectivities constituting the central nervous system for performing dominant roles for learning processes in mammals besides human [35]. More specifically, this motivation is supported by what revealed by National Institutes of Health (NIH) in USA that children in elementary school, may be qualified to learn "basic building blocks" of cognition and that after about 11 years of age, children take these building blocks and use them [36][37]. The extremely composite biological structure of human brain results in everyday behavioral learning brain functions. At the educational field, it is observable that learning process performed by the human brain is affected by the simple neuronal performance mechanism [38]. In this context, neurological researchers have recently revealed their findings about increasingly common and sophisticated role of Artificial neural networks $\left(\mathrm{ANN}^{\mathrm{s}}\right)$. Mainly, this role has been applied for systematic and realistic modeling of essential brain functions (learning and memory) [39]. Accordingly, neural network theorists as well as neurobiologists and educationalists have focused their attention on making interdisciplinary contributions to investigate observed educational phenomena associated with brain functional performance such as optimality of learning processes [6][[40][41][42].

Second Motivation: This motivation consider mainly the question :What Does The Brain Have To Do With Learning Process?. Referring to (Ned Herrmann, 2014), "The brain is involved in all aspects of the learning process. It is the single bodily organ that is the central processor of all learning activities." Blended learning is a blending of different learning methods, techniques and resources and applying them in an interactively meaningful learning environment. Interestingly, it is announced therein: ultimate aim of blended learning being to provide realistic practical opportunities for learners and teachers to make learning independent, useful, sustainable and ever growing. Current research shows that in order to achieve good blended learning results, there are three essential questions to answer when building a blended learning educational process is characterized by three main features as follows; 1. Learners: What is the best method for the target audience? 2. Learning Design: What is the best instructional model and delivery method for the content?

3. Learning Environment: What is the best method to meet your organizational constraints and requirements? Furthermore, some recently published papers which have announced developed findings of the considered future of BL is presented. These findings have been introduced at the four very recent published research papers : [44],[45],[46], and [47]. (Kintu et al.,2017)\&(Katherine Gotovsky, Cindy Lee, Jawad Bhimani, Kevin Ding, Marium Vahed, Rakeeb Hossain, Ryan Min, Ryan Yu, Sartaj Javed, and Tanya Nguyen,2017)\&(Rasheed F.,Wahid A.(2019)), and (Susan Mengel and others,2017). Therein, Blended learning is defined as the usage of various programs and applications in the provincial learning management system (LMS). It serves to supplement and teach learning in classes, equipping students with online tools to supplements face-to face lessons and web-based coursework. Also, these reference considered the application of realistic ANN modeling of e-learning and BL systems.

\subsection{A Block Diagram of Interactive Learning Processes Modeling}

This Block Diagram is based on a Neural Network model which composed of a set of biological neurons (nodes) represented as circles that depicted as circles (4-3-2) in Figure
1. Accordingly, that network's activity function is given by the Feed Forward Artificial Neural Networks (FFANN) structure presented schematically as follows:

1) The activity of the input comprises four nodes, represents the raw information that is fed into the network.

2) The activity for each node of the hidden layer is determined by the activities provided by the four input layer's nodes and the synaptic weights' connections between the input nodes and the hidden layer's nodes.

3) The behavioral activity of the output nodes depends on the activity of the hidden nodes and the weights between the hidden and output nodes.

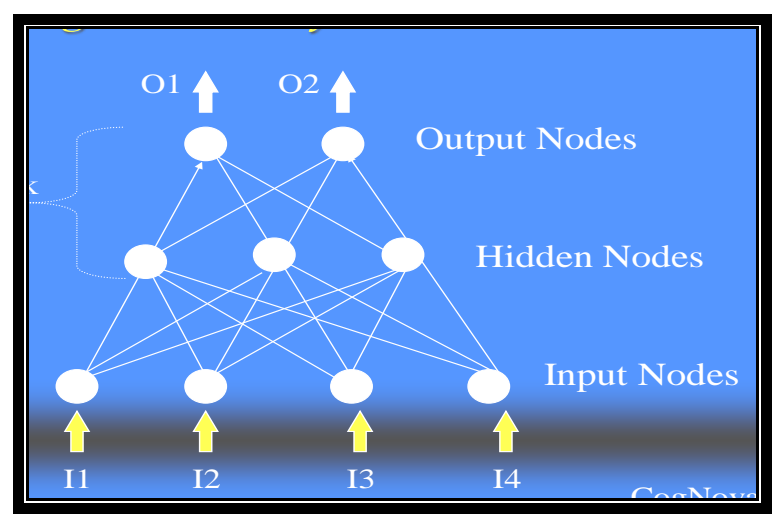

Figure 1. A simplified schematic diagram for a (FFANN) model (adapted from, [48] ).

A simplified block diagram for Artificial Neural Network model which simulating the Face to face interactive tuition process is presented at Figure 2. Inputs to the ANN learning / teaching model are provided by linking signals from the environmental in addition to correction signals provided by environmental stimuli in case of (unsupervised learning). However, in the case of learning using a teacher's guidance, the correction signal (s) is /are given as output response (s) of the model..That is evaluated under supervision of a teacher considering (supervised learning). Additionally, any tutor plays a role of improvement input data (stimulating learning pattern) by reducing the noise and redundancy of model pattern input. That is motivated by the tutor's experience while performing conventional (classical) learning. Consequently, the tutor provides the learning model with cleared data via maximizing of the signal to noise ratio [49]. Conversely, in the case of unsupervised/self-organized learning, which is based upon Hebbian learning rule [50] it is mathematically formulated by equation (7) presented at the next subsection $(C)$.

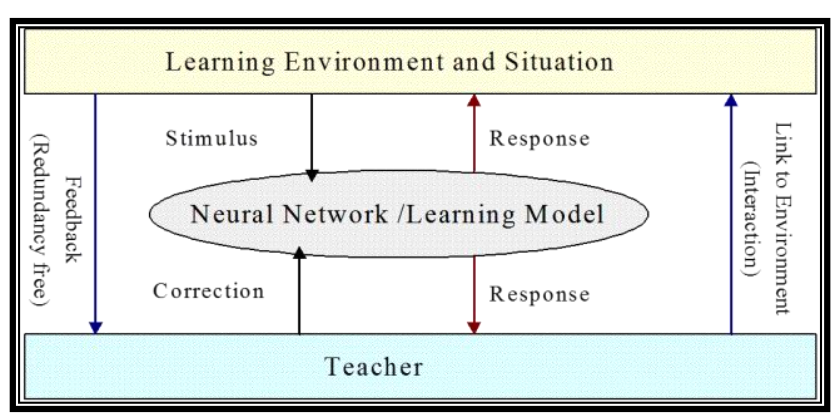

Figure 2. Simplified view for interactive learning process \{Adapted from [51]\}. 


\section{* Mathematical Formulation of Interactive Learning}

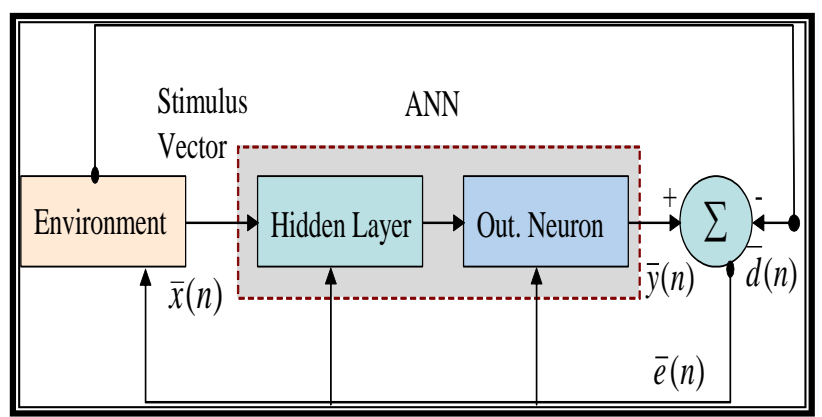

Figure 3. Generalized ANN block diagram simulating two diverse learning paradigms adapted from [52].

At Figure 3, an interactive learning model, that becomes in close similarity with a three layers FFANN given at figure 1 . That adopts correction feedback stimulating well qualified signals to perform realistic simulation for evaluating learner's performance. At Figure 2, illustrates inputs to the neural network learning model which provided by stimuli unsupervised by either learning environment or instructors' guiding correction signal [51]. The correction signal for the case of learning with a teacher is given by responses outputs of the model will be evaluated by either the environmental conditions (unsupervised learning) [53] or by the instructor. The instructor plays a role in improving the input data (stimulating learning pattern), by reducing noise and redundancy of learning model pattern input .In accordance with instructor's experience, he provides illustrated model with clear data by maximizing learning environmental signal to noise ratio [54]

By more details, referring to above Figure 4; the error vector

$\bar{e}(n)$ at any time instant (n) observed during learning

processes is given by:

$\bar{e}(n)=\bar{y}(n)-\bar{d}(n)$

Where $\bar{e}(n)=$ is the error correcting signal vector that is controlling adaptively the learning process outcome,

$\bar{y}(n)$ is the obtained outcome (output) signal developed by ANN model, and $\bar{d}(n) \ldots \ldots$ is the desired vector or numerical value(s). Moreover, the following four equations are deduced:

$$
V_{\mathrm{k}}(n)=X_{j}(n) W_{k j}^{T}(n)
$$

$Y_{\mathrm{k}}(n)=\varphi\left(V_{\mathrm{k}}(n)\right)=\left(1-\mathrm{e}^{-\lambda V_{\mathrm{k}}(n)}\right) /\left(1+\mathrm{e}^{-\lambda V_{\mathrm{k}}(n)}\right)$

$e_{\mathrm{k}}(n)=\left|d_{\mathrm{k}}(n)-y_{\mathrm{k}}(n)\right|$

$$
W_{\mathrm{lj}}(n+1)=W_{\mathrm{kj}}(n)+\Delta W_{\mathrm{kj}}(n)
$$

Where $X$ is input vector and $W$ is the weight vector. $\varphi$ is the activation function. $Y$ is the output. $e_{\mathrm{k}}$ is the error value and $d_{\mathrm{k}}$ is the desired output. Note that $\Delta W_{\mathrm{kj}}$ (n) is the dynamical change of weight vector value. Above four equations are commonly applied for both learning paradigms: supervised (interactive learning with a tutor), and unsupervised (learning though student's self-study). The dynamical changes of weight vector value specifically for supervised phase is given by:

$$
\Delta W_{\mathrm{kj}}(n)=\eta e_{\mathrm{k}}(n) X_{j}(n)
$$

Where $\eta$ is the learning rate value during the learning process for both learning paradigms. At this case of supervised learning, instructor shapes child's behavior by positive/ negative reinforcement Also, Teacher presents the information and then students demonstrate that they understand the material. At the end of this learning paradigm, assessment of students' achievement is obtained primarily through testing results. However, for unsupervised paradigm, dynamical change of weight vector value is given by:

$$
\Delta W_{\mathrm{kj}}(n)=\eta Y_{\mathrm{k}}(n) X_{j}(n)
$$

Noting that $e_{\mathrm{k}}(\mathrm{n})$ equation (6) is substituted by $y_{\mathrm{k}}(\mathrm{n})$ at any arbitrary time instant (n) during the interactive learning process. Referring to Figure 2, the correction signal which provided by a tutor should take into consideration the noisy environmental level inside classrooms (such as noisy crowdedness) .In other words, that level is quantitatively measured as signal to noise $(\mathrm{S} / \mathrm{N})$ ratio or equivalently the additive noise power $(\sigma$ ) to the ideally sensory clear signal. Consequently, the response time response measured by number of training cycles (n) $\{$ as defined at the subsection in the above $(B)$ by the two equations (6) \& (7) $\}$. Noting value of (n) should have been increased until reaching learning convergence instant, when:

$$
\Delta W_{\mathrm{kj}}(n)=0
$$

That above condition given by equation (8), could be fulfilled only if the desired output learning has been obtained after some number of training cycles learning convergence (response time) in fulfillment of the above two equations (6) $\&(7)$.

\section{REVISING OF TWO}

\section{FEEDBACK/ASSESSMENT CONCEPTS}

In this section, a brief presentation for educational assessment phenomenon basics have been introduced. It is well known that assessment issue has a broad and rapidly growing field, with a strong theoretical and empirical base [55]. However, an assessment expert couldn't be found who is capable to employ sound practices to guide any teaching process. That for obtaining more systematical investigation towards planning as well as implementation for programming of observed learning assessment phenomenon [56].The basic concepts needed to more systematic investigation of suggested assessment analysis and evaluation are presented at [57]. Formative: Given throughout the learning process, formative assessments seek to determine how students are progressing through a certain learning goal. Summative: Given at the end of the year or unit, summative assessments assess a student's mastery of a topic after instruction. The next two subsections $(A$, and $B)$ introduce a brief revising for formative assessment, summative assessment, and student's self-assessment respectively: Firstly, formative assessment which includes formal and informal processes teachers and students use together evidence for the purpose of improving learning. Secondly, summative assessment that provide evidence of student achievement for the purpose of making a judgment about 
student competence or program effectiveness. In their widely read article "Inside the Black Box," Mr. Black and Mr. Wiliam demonstrated that improving formative assessment raises student achievement. Now they and their colleagues report on a follow-up project that has helped teachers change their practice, and students change their behavior so that everyone shares responsibility for the students' learning [58]. Additionally, this work interestingly motivated by formative assessment and learning regulation for different mathematical conceptions published at [59]. Assessment is used in many ways in education. a good deal of attention is now given to its use in helping teaching, and learning, described as assessment for learning (A f L), or formative assessment. Here the focus is on assessment of learning, or summative assessment describe as assessment of learning (A O L), which is used to summarize what students know or can do at certain times in order to report achievement and progress [60][61].

\subsection{Formative Assessment}

Formative assessment is also known as Assessment for Learning that is defined as the process of seeking and interpreting evidence for use by learners and their teachers to decide where the learners are in their learning, where they need to go and how best to get there". It do not result in an evaluation. Information about what a student knows, understands and is able to do is used by both the teacher and the learner to determine where learners are in their learning and how to achieve learning goals. In more details, this kind of assessment refers to the gathering of information or data about student learning during a course or program that is used to guide improvements in teaching and learning. Furthermore, Formative assessment activities are usually lowstakes or no-stakes; they do not contribute substantially to the final evaluation or grade of the student or may not even be assessed at the individual student level. For example, posing a question in class and asking for a show of hands in support of different response options would be a formative assessment at the class level. Observing how many students responded incorrectly would be used to guide further teaching [62]. Therefore, this paper adopts that model capable for learning assessment via online testing for a virtual group of 500 students. These students have been subjected to twenty Multiple Choice Questions (MCQ ${ }^{\mathrm{s}}$ ), which concerned with some computer science curriculum. Herein, attention paid to search for optimal estimated penalty value in case of erroneous (incorrect) selected answers. These selected answers have been assigned freely (with randomized probability value) by any arbitrary virtual student member out of 500. Furthermore, By using suggested ANN model, a fairly unbiased estimated penalty values have been obtained after measuring simulated outcomes of proceeded $\mathrm{MCQ}^{\mathrm{s}}$ virtual testing sessions. During examination sessions, fixed number of $\mathrm{MCQ}^{\mathrm{s}}$ have been submitted to the student. Interestingly, examined students have provided with their ability to skip (freely at his request) all provided answers for any submitted question.

\subsection{Summative Assessment}

Conversely, to the above concept presenting formative assessment at subsection A, summative assessment is known as Assessment of Learning ( $A O L$ )results in an evaluation of student achievement. Referring to [63], Summative assessment aims to evaluate student learning and academic achievement at the end of a term, year or semester by comparing it against a universal standard or school benchmark. Summative assessments often have a high point value, take place under controlled conditions, and therefore have more visibility. Four types of summative assessment: End-of-term or midterm exams\& Cumulative work over an extended period such as a final project or creative portfolio\& End-of-unit or chapter tests, and Standardized tests that demonstrate school accountability are used. The goal of summative assessment is to evaluate student learning at the end of an instructional unit by comparing it against some standard or benchmark. Furthermore, unlike formative assessments' activities which usually have low-or no-stakes; often summative assessments have high stakes, which means that they have a high point value. They are usually include as examples : a midterm exam, a final project, a paper, and a senior recital. Interestingly, information from summative assessments can be used formatively when students or faculty use it to guide their efforts and activities in subsequent courses. Therein, at that reference, exploration for the extent to which assessment information can be used for both summative and formative purposes, without the use for one purpose endangering the effectiveness of use for the other.

\subsection{A Briefing Review of Interactive Blended Learning}

Blended learning is defined as the usage of various programs and applications in the provincial learning management system (LMS). Its philosophy is to simulate active learning, individual learning and learner centered learning strategy. Blended learning has a positive influence on the learning process as it is characterized with some advantages such as flexibility in both time and place of the study. More precisely, blended learning environment integrates the advantages of elearning method with some advantageous aspects of traditional method, such as face-to-face interaction. Blended learning brings traditional physical classes with elements of virtual education together[64] [Finn \& Bucceri, 2004]. Blended learning, is also known as mixed, sandwich, hybrid learning, is a method that conflate traditional learning environments in which led by teachers and technological based e-learning environments [65][66][67](Ayala, 2009; Young, 2002; Valiathan, 2002). During the process of choosing blended learning environments, the educators need to think about the skills that are being taught, learning resources, practicality, time and cost, learners' qualifications and suitable learning theories. The relation between Blended Learning and the traditional learning is illustrated schematically at the Figure 4. in below after [68] [Tayebinik, M., 2012] . Additionally, a similar figure is given at:[69] [Ceylan, V. K., \& Elitok Kesici, A. (2017)]. Referring to [70][Washington, D.C., 2009 US Dept of Education, 2010], therein it is stated that: "In studies contrasting blends of online and face-to-face instruction with conventional face-to-face classes, blended instruction has been more effective." Moreover. by referring to [71] Çobanoğlu and Ateş (2015; p.92) B-Learning's relation between Face to Face (F2f) learning and online learning via widespread definition. In $21 \mathrm{st}$ century, today's students represent the first generation to grow up with new technologies and are considered as the Zgeneration digital natives. They spend their entire lives surrounded by and using computers, videogames, digital music players, video cams, cell phones, and all the other toys and tools of the digital age. Today's average college graduates spend less than 5,000 hours of their lives reading, but over 10,000 hours playing video games (not to mention 20,000 hours watching TV) [72](Prensky, 2001). Computer games, email, the Internet, cell phones and instant messaging are integral parts of their lives. Accordingly, instructors should not ignore new developments in Educational Technologies, which create rich learning environments. Also, instructors 
should include digital materials to their learning environments so that more sharing and accessibility will be possible with the Z-generation students, who has new skills and interests in different instructional materials.

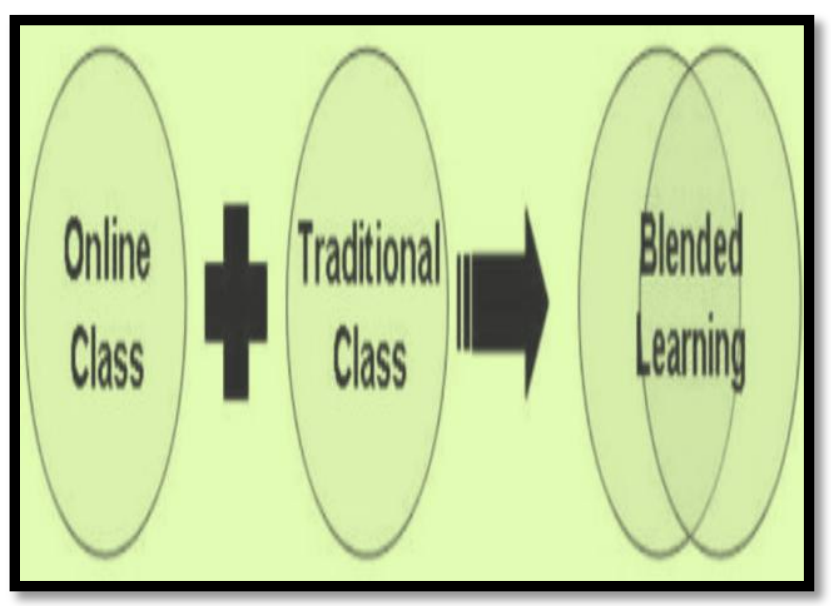

Figure 4. A Schematic Drawing that presents the construction of Blended Learning Environment.

\{Adapted From [Tayebinik, M., 2012]\}

\section{PRACTICAL FIELD EXPERIMENTAL RESULTS}

The obtained practical field results after experimental educational processes have been presented at this section by four tabulated numerical results as follows. At the two tables numbered as ( 1 \& 2), obtained practical results after performing experimental work by Computer Aided Learning (C A L) using different software packages. However at tables numbered as $(3 \& 4)$ presents results after some Blended

Table1. Illustrates students' marks after performing three educational experiments associated to CAL

\begin{tabular}{|c|ccccccccccccccc|}
\hline $\begin{array}{c}\text { Classical } \\
\text { Learning }\end{array}$ & 35 & 43 & 29 & 50 & 37 & 17 & 10 & 60 & 20 & 48 & 15 & 55 & 40 & 8 & 20 \\
\hline $\begin{array}{c}\text { CAL without } \\
\text { Voice }\end{array}$ & 39 & 29 & 52 & 60 & 50 & 68 & 62 & 30 & 55 & 42 & 40 & 59 & 48 & 70 & 2 \\
\hline CAL with Voice & 65 & 70 & 50 & 75 & 45 & 50 & 62 & 90 & 85 & 50 & 80 & 90 & 58 & 55 & 60 \\
\hline
\end{tabular}

Table 2. Illustrates statistical analysis of the above (Table 1.) obtained students' Academic Achievements (outcome marks)

\begin{tabular}{|c|c|c|c|c|c|}
\hline $\begin{array}{c}\text { Educational } \\
\text { Experimental } \\
\text { Methodology }\end{array}$ & $\begin{array}{c}\text { Students' } \\
\text { average } \\
\text { Achievement } \\
\text { score }\end{array}$ & $\begin{array}{c}\text { Variance } \\
\sigma\end{array}$ & $\begin{array}{c}\text { Standard } \\
\text { deviation } \\
\sqrt{\sigma}\end{array}$ & $\begin{array}{c}\text { Improvement } \\
\text { Coefficient of } \\
\text { variation } \rho\end{array}$ & $\begin{array}{c}\text { of Academic } \\
\text { Achievements } \\
{[\%]}\end{array}$ \\
\hline Classical & 32.46 & 265.32 & 16.28 & 0.50 & - \\
\hline $\begin{array}{c}\text { CAL(without } \\
\text { tutor's voice) }\end{array}$ & 46.80 & 297.49 & 17.24 & 0.36 & $44.1 \%$ \\
\hline $\begin{array}{c}\text { CAL(with } \\
\text { tutor's voice) }\end{array}$ & 64.33 & 283.42 & 16.83 & 0.26 & $98.2 \%$ \\
\hline
\end{tabular}


Table 3. Illustrates students' marks after performing three educational experiments associated to BL.

\begin{tabular}{|c|ccccccccccccccc|}
\hline $\begin{array}{c}\text { Classical } \\
(\text { F2F })\end{array}$ & 54 & 43 & 55 & 53 & 45 & 62 & 55 & 44 & 45 & 61 & 56 & 45 & 54 & 47 & 43 \\
\hline $\begin{array}{c}\text { Summative } \\
\text { FB/Assessment }\end{array}$ & 52 & 80 & 82 & 73 & 64 & 65 & 61 & 53 & 80 & 64 & 65 & 55 & 71 & 70 & 72 \\
\hline $\begin{array}{c}\text { Formative } \\
\text { FB /Assessment }\end{array}$ & 83 & 73 & 79 & 81 & 80 & 82 & 62 & 73 & 71 & 63 & 72 & 83 & 72 & 80 & 62 \\
\hline
\end{tabular}

Table 4. Illustrates statistical analysis of the above obtained (Table 3.) students' Academic Achievements (outcome marks).

\begin{tabular}{|c|c|c|c|c|c|}
\hline $\begin{array}{c}\text { Educational } \\
\text { Experimental } \\
\text { Methodology }\end{array}$ & $\begin{array}{c}\text { Students' } \\
\text { Average } \\
\text { Academic } \\
\text { Achievements } \\
(\mathbf{M})\end{array}$ & Variance $\sigma$ & $\begin{array}{c}\text { Standard } \\
\text { deviation } \sqrt{\sigma}\end{array}$ & $\begin{array}{c}\text { Coefficient of } \\
\text { variation }\end{array}$ & $\begin{array}{c}\text { Improvement } \\
\text { of academic } \\
\text { Achievements } \\
{[\%]}\end{array}$ \\
\hline Classical (F2F) & 50.8 & 40.02 & 6.32 & 0.124 & - \\
\hline $\begin{array}{c}\text { Summative } \\
\text { FB/Assessment }\end{array}$ & 67.13 & 85.04 & 9.22 & 0.137 & $\mathbf{3 2 . 1 4} \%$ \\
\hline $\begin{array}{c}\text { Formative } \\
\text { FB /Assessment }\end{array}$ & 75.2 & 42.29 & 6.5 & 0.086 & $\mathbf{4 8 . 0 3 \%}$ \\
\hline
\end{tabular}

\section{SIMULATION RESULTS AND INTERPRETATIONS}

Herein, one of ANN models' design parameters namely gain factor value $(\lambda \mathrm{i})$ has been adopted for explicit simulation for measuring the learners' individual differences, as an Index of learners' Learning Styles. That adopted parameter is motivated by Felder-Soloman Index of Learning Style (ILS) measures learners' styles [73][Felder, R. M., and Brent, R., 2005]. Variances on students' blended learning perception according to learning style preferences. The gain factor values ( $\lambda \mathrm{i}$ ) could be considered relevantly to represent learners' individual differences including their intrinsic characteristics, preferences, and personalities. That is simulated by various gain factor (slope) values and different neurons' number as well, contributing to the learning process. In Figure 5, a general normalized ANN learning model is shown as a set of performance curves. It represents various gain factor values (denoted by $\lambda$ design parameter). This set of $\lambda_{i}$ values are originated from the odd sigmoid activation function given by:

$y(t)=\frac{1-e^{-\lambda t}}{1+e^{-\lambda t}}$

For

$$
0 \leq t \leq \infty
$$

By changing values of this parameter, results in various response time (speeds)in reaching optimum (desired) achievements in accordance with the following equation:.

$\mathrm{Y}(\mathrm{n})=\left(1-\exp \left(-\lambda_{\mathrm{i}}(\mathrm{n}-1)\right)\right) /(1+\exp (-\lambda \mathrm{i}(\mathrm{n}-1)))$

(10)

Where $\lambda_{\mathrm{i}}$ represents one of gain factors (slopes) for odd sigmoid function given by equation (8) and (n), represents the learning convergence (response) time expressed in number of training cycles (epochs).

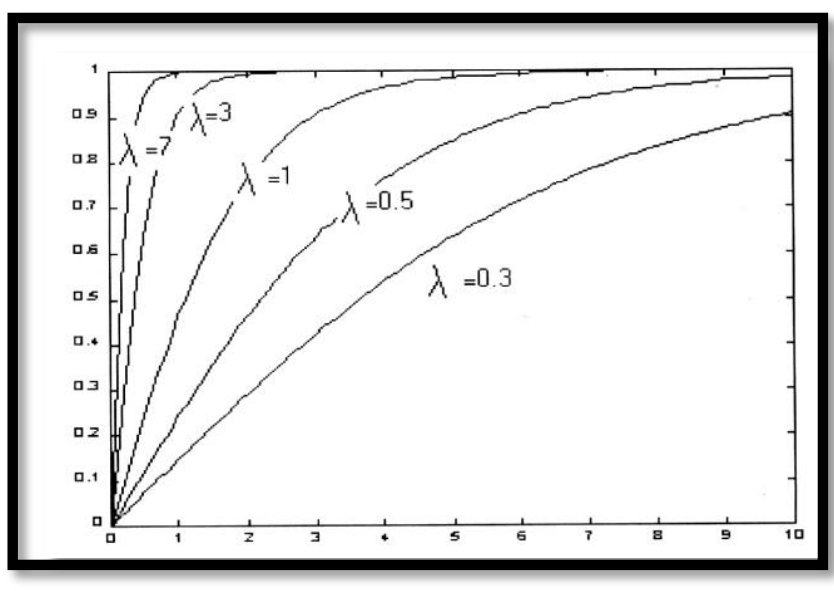

Figure 5. A set of personalized intrinsic learners' performance curves of model with various learning styles' values that corresponded to gain factor $(\lambda)$ values.

Referring to some recently findings announced at [74][Chang, 2014]. These findings illustrated that: (a) There were no significant differences in academic achievement test scores between blended e-learning and traditional (face to face) learning; (b) students in the experimental group obtained significantly higher scores on self-assessment than students in the supervised control experimental group; (c) students' academic achievement test scores on self-assessment were significantly higher after studying through blended e-learning than before.

\section{EFFECT OF NEURON'S NUMBER ON LEARNERS' SCORES}

Figure 6 introduces the flowchart for simulation program which applied for performance evaluation of behavioral learning processes. That Figure presents a simplified macrolevel flowchart which briefly describes the algorithmic steps for realistic simulation program of adopted Artificial Neural Networks' model for different number of neurons. The 
obtained depicted three graphs at Figures 7 and the other tree graphs shown at Figure 8 have been derived after running of simulation program for different neurons' number following feedbacks/assessments that simulated by different learningrate values $(0.05,0.1$, and 0.3$)$. Noting, these values $\eta_{\text {simulate }}$ respectivel the three educational methodologies (F2F \& Summative, and Formative) FB/Assessments. Interestingly, both figures consider the individual differences of learners as each of them characterized by his own fixed intrinsic Gain Factor Value $(\lambda)$.Similarly, the three obtained graphs depicted at Figures 9 (representing the academic achievement outcome) and the other three graphs given at Figure 10 (representing the learning convergence time). Both have been derived after running of simulation program for different Gain Factor $(\lambda)$ values which correspond to intrinsic individual learners' differences, and different number of neurons contributing to learning process. Interestingly, both figures consider the individual differences of learners as each of them characterized by his own intrinsic graph (Gain Factor $(\lambda)$ value), for fixed learning rate value $\eta=0.3$.

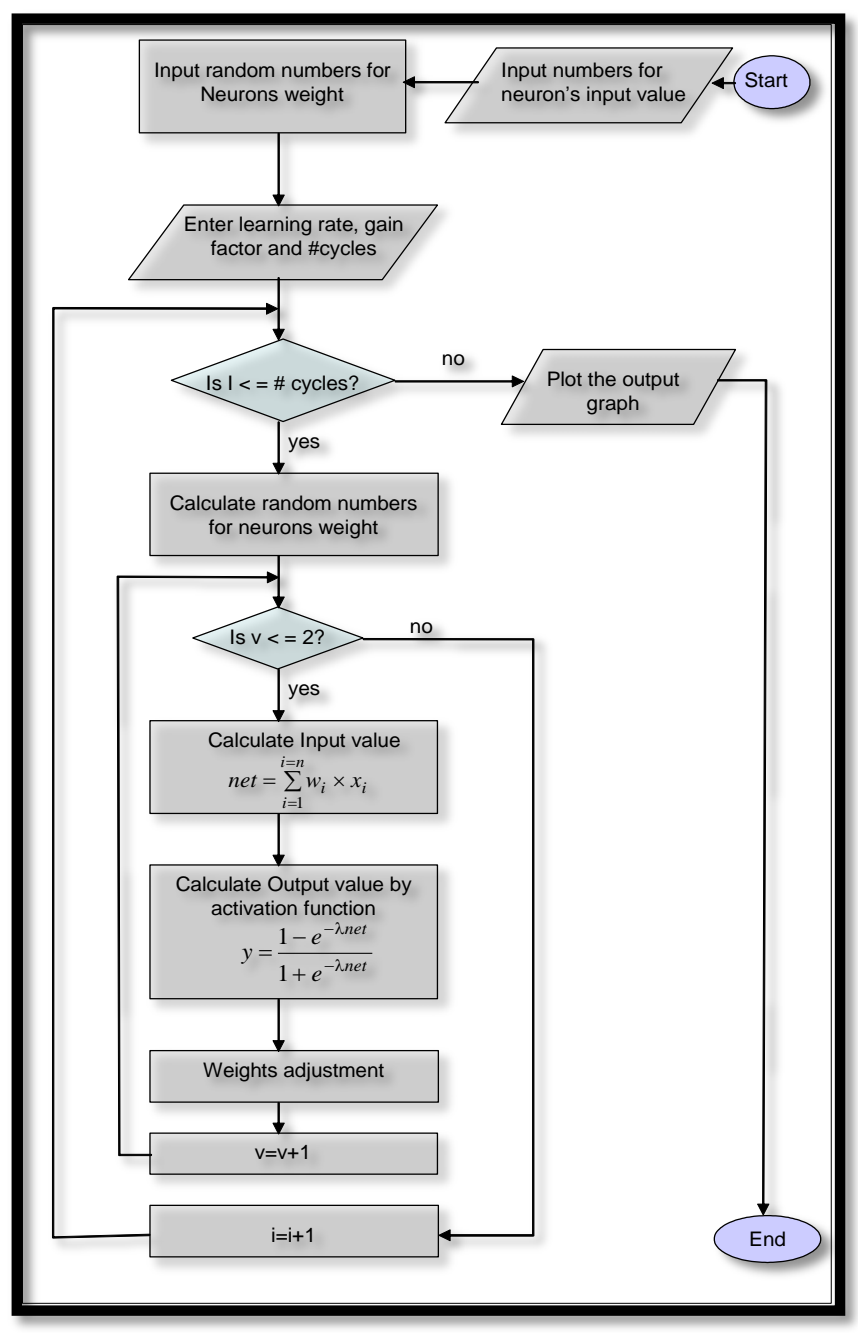

Figure 6. A simplified macro level flowchart that describing algorithmic steps for Artificial Neural Networks modeling considering various neurons' number.

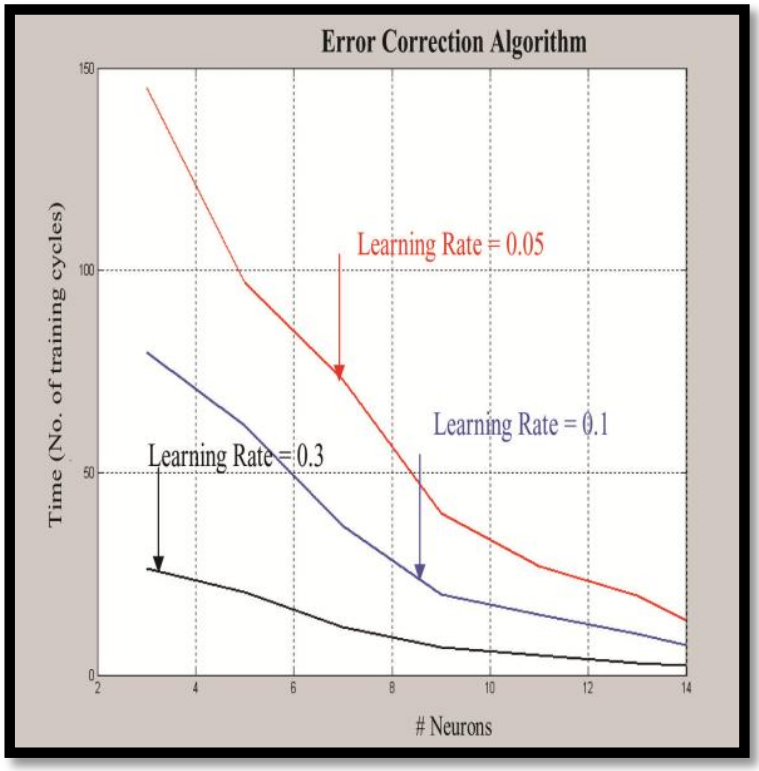

Figure 7. Illustrates learning by using error correction algorithm based on time response (learning convergence)parameter that is measured by No. of training cycle for three different learning rate values $\eta$ $(0.05,0.1$, and 0.3$)$ considering the fixed value of gain factor $=0.5$

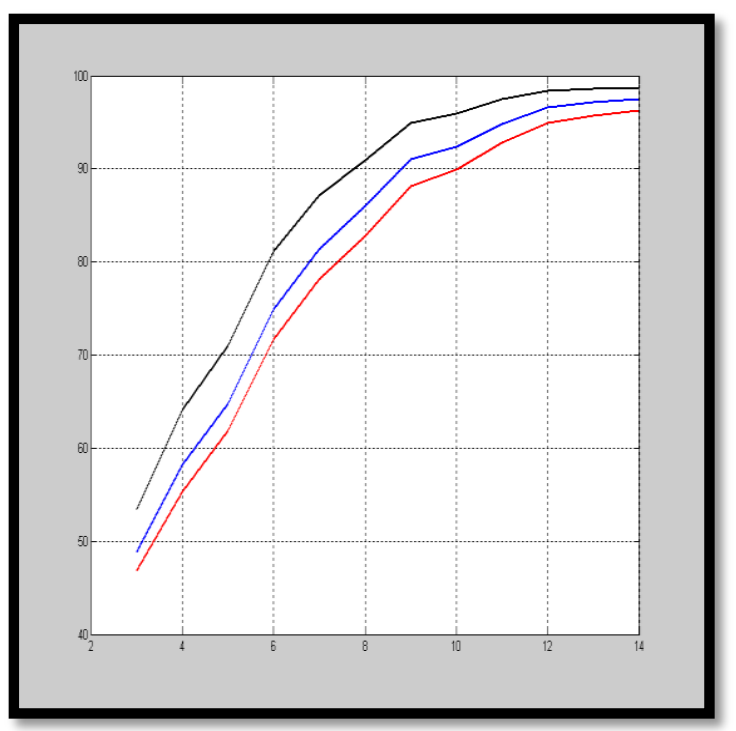

Figure 8. Illustrates simulated academic achievements (learning outcomes) presented as normalized degree versus \# Neurons for different learning rate values $\eta$ $(0.3,0.1$, and 0.05$)$ and constant gain factor $=1$. These values of learning rate parameter $\eta$ values are observed to be inversely proportion to the corresponding educational noisy environment. 


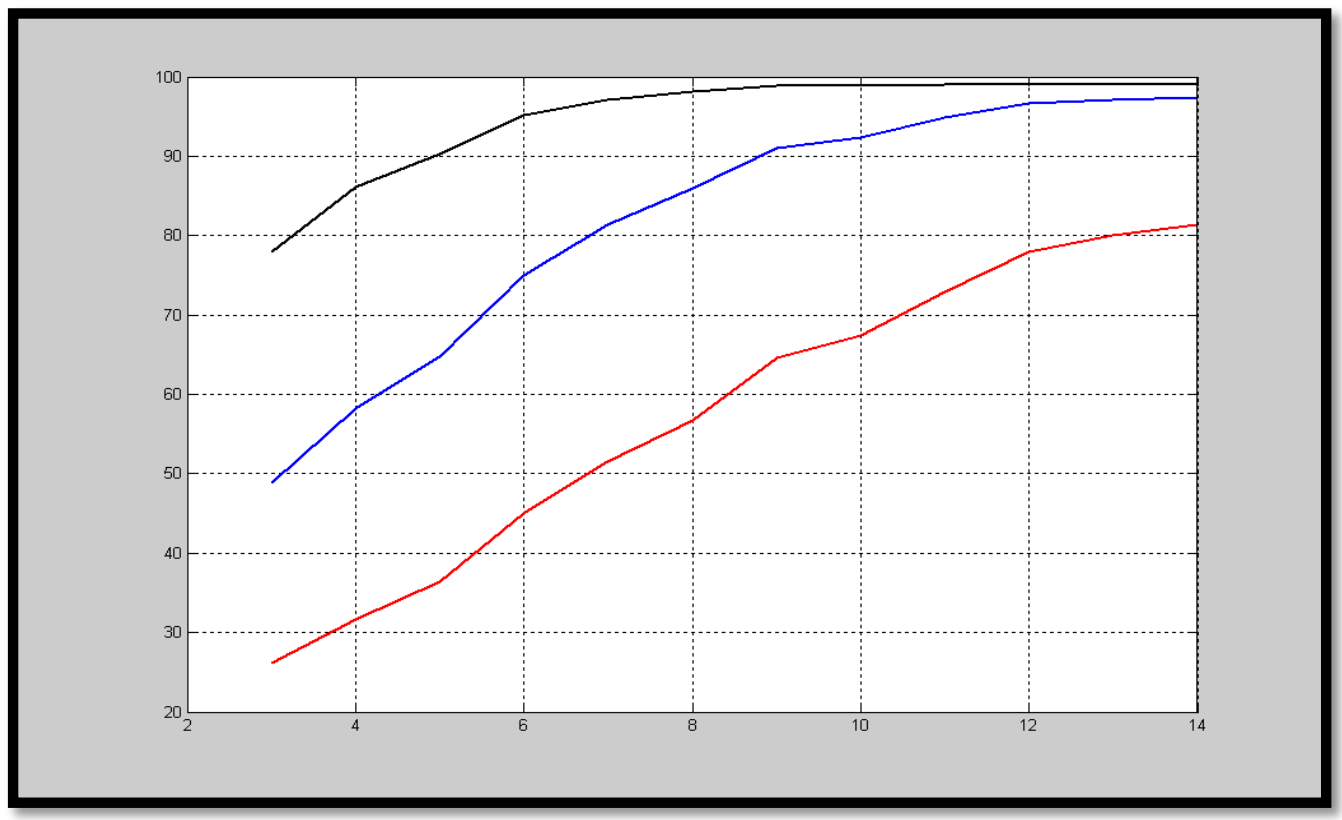

Figure 9. Illustrate students' academic achievement for versus different gain factor values $(0.5,1$, and 2$)$ when fixed \# training cycles $=300$, and learning rate value $=0.3$.

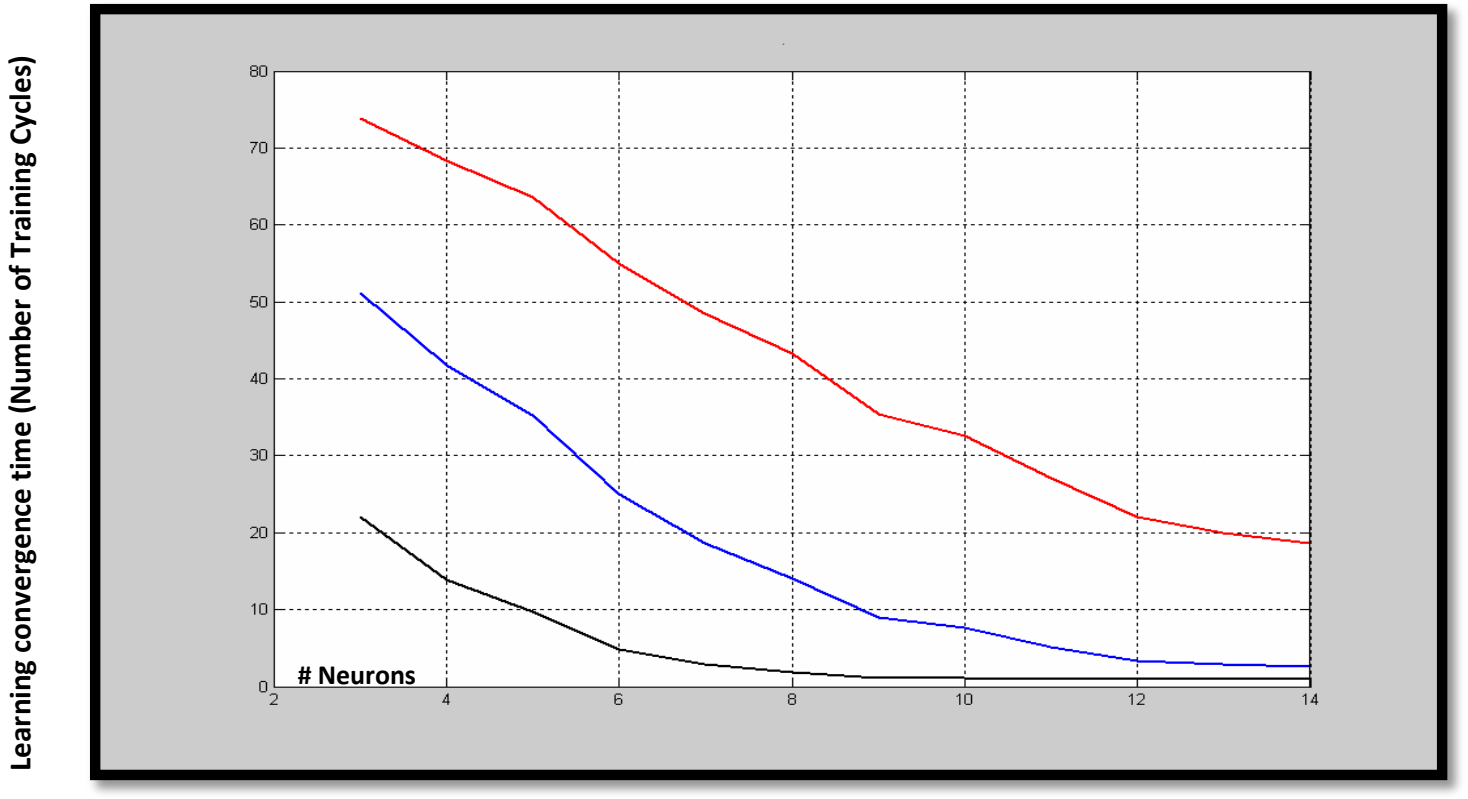

Figure 10. Illustrates time response (learning convergence time)parameter that measured by No. of training cycle for three different gain factor values $(0.5,1$, and 2$)$ by fixed learning rate value $=0.3$.

\section{CONCLUSIONS}

This research work adopted the novel interdisciplinary and challenging research approach tightly coupled to the application of realistically ANN modeling of the BL, Elearning, individual learners' differences, such as that introduced by six papers [76]\&[77]\&[78]\&[79]\&[80], and [81]. More precisely, analysis and evaluation of Formative, or Summative feedback/assessments for e-learning systems, BL, and CAL packages have been adopted by using realistic ANN modeling . In other words, it is motivated by pieces of research integrating three fields of : education, cognitive science, and psychology with computer science and neurobiology to searching for optimality of the ways to learn. Noting that "By Understanding how we learn we can increase the ability to learn" as has been stated by Professor Lili
Saghafi at [75](Saghafi, 2015). Specifically, the introduced work inspired by a strong belief that interdisciplinary combining of realistic Artificial Neural Networks (ANNS) modeling with observed challenging phenomenal educational issues such as e-learning, and Blended Learning for introducing its investigational study, analysis, and evaluation.

Accordingly, neural networks' theorists as well as educationalists have recently working together focusing their attention on searching for optimal realistic simulation and modeling of some selected critical educational issues. That's results in an ANN model contributing to optimal investigation of teaching/learning performance functions such as distinct assessment procedures formative ( $\mathrm{A} \mathrm{L}$ ), and summative( $\mathrm{A}$ $\mathrm{O} \mathrm{L})$ \}. Interestingly, it is revised that (A f L), did predict a substantial amount of course outcome and its validity 
observed to pave the way for diagnostic use and remedial teaching. However, (A O L) is focused on summarizing what students know or can do at certain times in order to report their academic progress, and achievement. Specifically, this piece of research considers the modeling of importance of summative assessment procedures in harmony with procedures of formative assessment by implementation of a relevant software computer assessment package in addition to considering the different number of neurons contributing to learning process.

\section{REFERENCES}

[1] "What is Technology-Mediated Learning (TML)?" Availableonlineat:https://www.igiglobal.com/dictionary/ why-studying-individual-differences-in-call/49265

[2] Balderas "The influence of information technology in the daily work of mathematics teachers" . Available online at: http://math.unipa.it/ grim/EBalderas.PDF

[3] M. D. Roblyer, and Aaron H. Doering "Integrating Educational Technology into Teaching (6th Edition)". Publication Date: January 6, 2012 ISBN-10: 0132612259 | ISBN-13: 978-0132612258 | Edition: 6 Available online at: http://www.amazon.com/IntegratingEducational-Technology-into- Teaching/dp/0132612259

[4] Hunsader, Patricia D.; Thompson, Denisse R.; Zorin, "Engaging Elementary Students with Mathematical Processes During Assessment: What Opportunities Exist in Tests Accompanying Published Curricula? Source: International Journal for Mathematics Teaching \& Learning. 2013, p1-25. 25 p.

[5] Hassan M. H. Mustafa ,et.al." On Optimality of Teaching Quality for a Mathematical Topic Using Neural Networks (With a Case Study)" .Published at EDUCON 13 conference which held in Berlin, Germany from 1315 March 2013.

[6] H. M. Mustafa, Ayoub Al-Hamadi, and Mohammed H. Kortam "On Assessment of Teaching a Mathematical Topic Using Neural Networks Models (With a case study)" Published at COMPUTER SCIENCE AND APPLICATION, VOL. 1, NO. 2, FEBRUARY, 2012, pp.12-19. The paper is also available online at : http://researchpub.org/journal/csa/number/vol1-no22.pdf

[7] HORGAN J. (1993), The death of proof. Scientific American, n. 10, 74-82.

[8] (Aragón, 96) "The influence of information technology in the daily work of mathematics Teachers" Angel Balderas Puga. Available online at: http://math.unipa.it/ grim/EBalderas.PDF

[9] KENT P. \& NOSS R. (1998), The Visibility of Models: Using technology as a bridge between mathematics and engineering, Proceedings of the ICMI Study Conference "On the teaching and Learning of Mathematics at University Level", Singapore. This conference paper has been published on January 1998, at the International Journal of Mathematical Education 31(1) DOI 10.1080/002073900287390. Available online at: https://www.researchgate.net/publication/229023022_Th e_visibility_of_models_Using_technology_as_a_bridge_ between_mathematics_and_engineering.
[10] Interactive practice with long division with no decimals: Daisy Maths - Long Division http//Argyll.epsb.ca /jreed/ extras / longdiv

[11] Long Division: A Touch-Stone for a Few Teaching Principles. Available on line at: www.math.technion.ac.il/ ra/englongdivision.doc

[12] H. M. Mustafa, and Ayoub Al-Hamadi "On Teaching Quality Improvement of A Mathematical Topic Using Artificial Neural Networks Modeling" (With A Case Study)". Published at 10th (Anniversary!) International Conference Models in Developing Mathematics Education". Hold in Dresden, Saxony, Germany on September 11-17, 2009.

[13] Hassan M. H. Mustafa et al. "On Improvement of Teaching Quality for a Selected Mathematical Topic Using Artificial Neural Networks Modeling (With a Case Study)" Journal of Literature and Art Studies Volume 7, Number 2, Feb. 2017 (Serial Number 63) David Publishing Company, USA. 2159-5836 (Print), ISSN 2159-5836 (Print), ISSN 2159-5844 (Online), pp. 239246

[14] Al-Zahrani, F.A., Mustafa, H.M., and Al-Hamadi, A. (2010) "On Analysis And Evaluation of Multi-Sensory Cognitive Learning Of A Mathematical Topic Using Artificial Neural Networks", Journal of Telecommunications, 1(1), 99-104.

[15] Brianna Flavin "8 Surprising Ways Computer Science Benefits Society [2018 \& Beyond]-"Why is computer science important?" This article was originally published in December 2015. It has since been updated to include information relevant to 2018. Retrieved on 08/29/2018onlineat:https://www.rasmussen.edu/degrees/t echnology/blog/ways-computer-science-benefits-society/

[16] " online courses increase access to education? ". Published on Jan 24, 2017 11:34 AM EST by NBER Digest.AvailableOnlineat:https://www.pbs.org/newshour /economy/only courses-increase-access-education.

[17] Levit, Alexandra. (2015). The Future of Education According to Generation Z. Time. Retrieved from http://time.com/3764545/future-of-education/?scrlybrkr.

[18] "The Future Of Massively Open Online Courses (MOOCs)" Available online at https://www.forbes.com/sites/quora/2017/03/23/thefuture-of-massively-open-online-coursesmoocs/\#4236df526b83

[19] Aditya Mohan "What according to you is the future of MOOCs?".Retrieved on:https://www.quora.com/Whataccording-to-you-is-the-future-of-MOOCs.

[20] Sharma, Pramod. (2016). World of Comenius. Tech Crunch. Retrieved from: https://techcrunch.com/tag/world-of-comenius/.

[21] Moynihan, Tim. (2016). Google is bringing its VR field trips to even more schools.Wired.Retrievedfrom https://www.wired.com/2016/01/google-brings-itsvrfield-trips-to-more-schools/.

[22] .Reede, Elizabeth. (2016). When Virtual Reality meets Education.TechCrunch.Retrievedfromhttps://techcrunch. com/2016/01/23/when-virtual realitymeets-education/. 
[23] Fahs, C. (2016). CS50 Moves Away from Traditional Lectures, Toward Virtual Reality. The Harvard Crimson. Retrievedfromhttp://www.thecrimson.com/article/2016/8 /31/CS50-moves-fromlectures/.

[24] Stein, J., \& Graham, C. R. (2014). Essentials for Blended Learning: A Standards-Based Guide. New York: Routledge.

[25] Bayram Güzer, and Hamit Caner "The past, present and future of blended learning: an in depth analysis of literature" Published at the proceeding of the 5th World Conference on Educational Sciences - WCES 2013.

[26] Jennifer Hofmann "Proving the Value of Blended Learning" Posted on Feb 6, 2017 12:05:00 PM. Availableonlineat:https://blog.insynctraining.com/26proving-the-value-of-blended-learning

[27] Journal Teaching English with Technology. Year. 2016. Volume. 16. Issue. 3 , pp.103-107, Available online at: http://www.tewtjournal.org

[28] Higgs, Alison (2015). Effective Feedback in Blended learning. In: Conference Proceedings: The Future of Education, libreiauniversitaria.it, Padova.

[29] Claire Johnson "Blended learning: What is it and why should you try it? Learning enthusiast and biology nerd April 23, 2018. Available online at : https://blog.labster.com/what-is-blended-learning

[30] (Wimshurst \& Manning 2013). "Feed-forward assessment, exemplars and peer marking: evidence of efficacy" Pages 451-465 | Published online: 18 Jan 2012 at: https://doi.org/10.1080/02602938.2011.646236

[31] Wesolowski M, Suchacz B. Artificial neural networks: theoretical background and pharmaceutical applications: a review. J AOAC Int. 2012 May-Jun;95(3):652-68.

[32] https://www.google.com.sa/search?q=error+correction+1 earning+in+neural+network\&sa $=X \& v e d=2 a h U K E w i i i e L$ W28DfAhUCixoKHamMDk4Q1QIoAHoECAIQAQ\&bi $\mathrm{w}=1366 \& \mathrm{bih}=608$

[33] Error correction learning in Artificial neural networks. Available online at: https://en.wikibooks.org/wiki/Artificial_Neural_Network s/Error-Correction_Learning

[34] White House OSTP Issues Decade of the Brain Report, Maximizing Human Potential: 1990-2000.

[35] Douglas, R. J., \& Martin, K. A. C. (1991). Opening the gray box. Trends in Neurosciences, 14, 286-293.

[36] Swaminathan, N 2007 " Cognitive Ability Mostly Developed Before Adolescence, NIH Study Says. NIH announces preliminary findings from an effort to create a database that charts healthy brain growth and behavior -Scientific American letter, May 18, 2007.

[37] Swaminathan, N "How The Brain Maps Symbols To Numbers" Scientific American letter, October 31, 2007.

[38] Borzenko "Neuron mechanism of human languages" Published in IJCNN'09 Proceedings of the 2009 international joint conference on Neural Networks IEEE Press Piscataway, NJ, USA (02009 ISBN: 978-1-42443549-4.

[39] H.M. Hassan ,A. Al-Hamadi, B. Michaelis" Evaluation of Memorization Brain Function Using a Spatio-temporal
Artificial Neural Network (ANN) Model" Published at CCCT 2007 conference held on July12-15,2007Orlando, Florida, USA.

[40] Mustafa, et. al. -On Assessment of Brain Function Adaptability in Open Learning Systems Using Neural Networks Modeling (Cognitive Styles Approach)\| published at The IEEE International Conference on Communications and Information Technology ICCIT2011, held on Mar 29, 2011 - Mar 31, 2011, Aqaba, Jordan. Published also at Journal of American Science, 2011: 7(4), http://www.americanscience.org.

[41] H.M. Mustafa - Building up bridges for natural inspired computational models across behavioral brain functional phenomena; and open learning systems\| A tutorial presented at the International Conference on Digital Information and Communication Technology and its Applications (DICTAP2011) held from June 21-23, 2011 , at University de Bourgogne, Dijon, France.

[42] Kristin L. McGraner, "Preparation of Effective Teachers in Mathematics", ATQ Connection Issue Paper on Applying the Innovation Configuration to Mathematics Teacher Preparation\| January 2011. Available online at http://www.tqsource.org/pdfs/TQ_IssuePaper_Math.pdf.

[43] Ned Herrmann (2014) "The What and Why of the Blend Trend " The Whole Brain Business Book- Updated version! McGraw Hill 14 may 2014. Available online at:http://www.herrmannsolutions.com/the-whole-brainbusiness-book/

[44] Kintu et al."Blended learning effectiveness: the relationship between student characteristics, design features and outcomes" International Journal of Educational Technology in Higher Education (2017) 14:7,DOI 10.1186/s41239-017-0043-4

[45] Katherine Gotovsky, Cindy Lee, Jawad Bhimani, Kevin Ding, Marium Vahed, Rakeeb Hossain, Ryan Min, Ryan Yu, Sartaj Javed, and Tanya Nguyen "FUTURE OF BLENDED LEARNING IN EDUCATION:A REPORT FOR STUDENTS AND POLICY MAKERS" (C) 2017 Federation of Canadian Secondary Students. Available onlineat:.https://static1.squarespace.com/static/53c2060a e4b0db3d3fa5937f/t/591ca78f6a49632377fa8fd5/149505 0128097/F uture+of+Blended+Learning.pdf.

[46] Rasheed F., Wahid A. (2019) Learning Style Recognition: A Neural Network Approach. In: Bapi R., Rao K., Prasad M. (eds) First International Conference on Artificial Intelligence and Cognitive Computing. Advances in Intelligent Systems and Computing, vol 815. Springer, Singapore. First Online: 05 November 2018 Available online at:First International Conference on Artificial Intelligence and Cognitive Computing

[47] Susan Mengel, and others : "On the use of neural networks in intelligent tutoring systems." This article in International Journal of Artificial Intelligence in Education - February 1991. All content following this page was uploaded by Susan Mengel on 16 March 2017. Available on Aug. 1, 2018 from: https://www.researchgate.net/publication/262280236_On _the_use_of_neural_networks_in_intelligent_tutoring_sy stems

[48] J R Soc Interface. 2007 Apr 22; 4(13): 193-206. Published online 2006 
[49] H.M. Hassan" On Simulation of Adaptive Learner Control Considering Students' Cognitive Styles Using Artificial Neural Networks (ANNs)" Published at CIMCA, Austria. 28-30 Nov.2005.

[50] D.O. Hebb, "The organization of behaviour", Wiley, New York (1949).

[51] Hassan. M. Mustafa and Ayoub Al-Hamadi "On Comparative Analogy of Academic Performance Quality Regarding Noisy Learning Environment versus Nonproperly Prepared Teachers Using Neural Networks' Modeling" .Published in International Journal of Information and Education Technology, Vol. 6, No. 12, December 2016.

[52] Haykin S., Neural Networks, Englewood Cliffs, NJ: Prentice-Hall, 1999.Nov.28. doi: 10.1098/rsif.2006.0177

[53] M.Fukaya, et.al "Two level Neural Networks: Learning by Interaction with Environment", 1st ICNN, San Diego, (1988)

[54] Ghonaimy M.A., Al - Bassiouni, A.M. and Hassan, H.M "Leaning Of Neural Networks Using Noisy Data". Second International Conference on Artificial Intelligence Applications, Cairo, Egypt, Jan 22-24, 1994. PP. 387-399.

[55] Dylan Wiliam "Keeping learning on track: Formative assessment and the regulation of learning" MAKING MATHEMATICS VITAL: PROCEEDINGS OF THE TWENTIETH BIENNIAL CONFERENCE OF THE AUSTRALIAN ASSOCIATION OF MATHEMATICS TEACHERS Learning and Teaching Research Centre, Educational Testing Service, pp.20-34. Available on line at:http://www.google.com.sa/url?sa=t\&rct $=j \& q=\&$ esrc $=s$ $\&$ frm $=1 \&$ source $=$ web $\& c d=1 \&$ ved $=0 C C$ sQFjAA\&url $=\mathrm{ht}$ tp $\% 3 \mathrm{~A} \% 2 \mathrm{~F} \% 2 \mathrm{Fassessment.tki.org.nz} \% 2 \mathrm{Fcontent} \% 2 \mathrm{Fdo}$ wnload $\% 2 \mathrm{~F} 3713 \% 2 \mathrm{~F} 26542 \% 2 \mathrm{Fversion} \% 2 \mathrm{~F} 1 \% 2 \mathrm{Ffile} \% 2$ FWilliam\%2C\%2BD.\%2C\%2BKeeping\%2BLearning\% 2Bon\%2BTrack\%2BFormative\%2Bassessment $\% 2 \mathrm{Band}$ $\%$ 2B the \%2Bregulation $\% 2 \mathrm{Bof} \%$ 2Blearning.pdf\&ei $=$ n7ic UsugFsPwhQfY3oHYBQ\&usg=AFQjCNGxlZ44vne1fY zTL69ZnzUg6I6ibg

[56] Hassan M. H. Mustafa et. al -On Assessment of Brain Function Adaptability in Open Learning Systems Using Neural Networks Modeling (Cognitive Styles Approach)\| published at The IEEE International Conference on Communications and Information Technology ICCIT2011, held on Mar 29, 2011 - Mar 31, 2011, Aqaba, Jordan. Published also at Journal of American Science, 2011: 7(4), http://www.americanscience.org.

[57] Hassan M. H. Mustafa "Modeling of Computer-Aided Assessment for a Selected Mathematical Topic Using Neural Networks". Published at ID.WCEECS-2014ICETC-Edas-1569926197-1 Tunisia 13-15 Jun. 2014. Published also at the International Journal of Engineering Science and Innovative Technology (IJESIT) Volume 3, Issue 3, May 2014-ISSN: 2319-5967 ISO 9001:2008 Certified.

[58] PAUL BLACK, CHRISTINE HARRISON, CLARE LEE, BETHAN MARSHALL, AND DYLAN WILIAM Working "Inside the Black Box: Assessment for Learning in the Classroom, Phi, Delta, Kappa, Vol. 86 \# 1,pp.821,2004http://web.uvic.ca/ gtreloar/Assessment/P eriodical\%20Items/Working\%20Inside\%20the\%20Black
\%20BoxAssessment\%20for\%20Learning\%20in\%20the $\% 20$ Classroom.

[59] The role of teachers in the assessment of learning (English).Availableonlineat:http://webarchive.nationalarc hives.gov.uk/20110809101133/http:/assessment-reformgroup.org/ASF\%20booklet\%20English.pdf

[60] Question Mark for Assessment Management, Create, Deliver, and Deliver. Available online at: https://www.questionmark.com/us/Pages/default.aspx

[61] S. G. Millard "Computer aided learning (CAL) and computer aided assessment (CAA) in civil engineering". Published at Proceedings of the 3rd International CDIO Conference, MIT, Cambridge, Massachusetts, USA, June 11-14, 2007.

[62] Hassan M. H. Mustafa et al "Optimal Estimation of Penalty Value for on Line Multiple Choice Questions Using Simulation of Neural Networks and Virtual Students' Testing" Published at International Journal of Engineering Science and Innovative Technology (IJESIT) Volume 3, Issue 2, March 2014.

[63] Types of summative assessment and formative assessment Available online on : 09/01/18 at: https://resourced.prometheanworld.com/types-ofsummative-formative-assessment/

[64] Finn, A., \& Bucceri, M. (2004). A case study approach to blended learning, retrieved January 15, 2008 from http://www.centra.com/download/whitepapers/CaseStud y_BlendedLearning.pdf.

[65] Ayala, J. (2009). Blended Learning As A New Approach To Social Work Education. Journal of Social Work Education Volume 45, Issue 2

[66] Young, J.R. (2002). Hybrid Teaching Seeks To End The Divide Between Traditional And Online Instruction. The Chronicles Of Higher Education, A33. 19.05.2015, http://chronicle.com/article/Hybrid-Taching-Seeksto/18487

[67] Valiathan, P. (2002). Blended Learning Models.Learning Circuits.18.02.2015.www.learningcircuits.org/2002/aug2 002/valiathan.html

[68] Tayebinik, M., \& Puteh, M. (2012) "Blended Learning or E-learning?" published at International Magazine on Advances in Computer Science and Telecommunications (IMACST), 3(1), 103-110.

[69] Ceylan, V. K., \& Elitok Kesici, A. (2017). Effect of blended learning to academic achievement. Journal ofHumanSciences, 14(1),308320.doi:10.14687/jhs.v14i1. 4141.thispublicationisavailableonlineat:https://www.rese archgate.net/publication/313683225

[70] Washington, D.C., 2009 US Dept of Education, 2010, U.S. Department of Education, Office of Planning, Evaluation, and Policy Development, Evaluation of Evidence-Based Practices in Online Learning: A MetaAnalysis and Review of Online Learning Studies,

[71] Çobanoğlu, A. ve Altun, E. (2015). Geleneksel öğretimden Harmanlanmış Öğrenme Temelli Öğretime, Eğitim Teknolojileri Okumaları s.89-107, Ankara.

[72] Prensky, M. (2001). Digital natives, digital immigrants. On the Horizon MCB University Press, Vol. 9 No. 5. October 2001. 
[73] Felder, R. M., and Brent, R. (2005). Understanding student differences. Journal of Engineering Education, 94(1),5772.Retrievedfrom:http://www4ncsu.edu/unity/lo ckers/users/f/felder/public/Papers/UnderstandinDifferenc es.pdf

[74] Chi-Cheng Chang; Kuen-Ming Shu; Chaoyun Liang; JuShih Tseng; Yu-Sheng Hsu (2014) "Is Blended eLearning as Measured by an Achievement Test and SelfAssessment Better than Traditional Classroom Learning for Vocational High School Students?" Published at // International Review of Research in Open \& Distance Learning; Apr 2014, Vol. 15 Issue 2, p213.

[75] Lili Saghafi (2015) "The Way We Learn". Available onlineat:https://www.slideshare.net/featured/category/ed ucation , Published on Jan 28, 2015

[76] Mohamed Sayed, and Faris Baker "E-Learning Optimization Using Supervised Artificial NeuralNetwork" Journal of Software Engineering and Applications, 2015, 8, 26-34 Published Online January 2015 in SciRes. http://www.scirp.org/journal/jsea http://dx.doi.org/10.4236/jsea.2015.81004 .

[77] Hassan M. H. Mustafa "On Brain Based Modeling of Blended Learning Performance Regarding learners' Selfassessment Scores Using Neural Networks (Brain Based Approach)". Published at IABL-2016 the IABL conference International Association for Blended Learning (IABL) will be held in Kavala Greece on 22-24 April 2016.

[78] Nick Z. Zacharis"PREDICTING TUDENT ACADEMIC PERFORMANCE IN BLENDED LEARNING USING ARTIFICIAL NEURALNETWORKS'. Published at
International Journal of Artificial Intelligence and Applications (IJAIA), Vol. 7, No. 5, September 2016.

[79] Hassan M. H. Mustafa et al "An Overview on Evaluation of E-Learning/Training Response Time Considering Artificial Neural Networks Modeling." Paper Published in Journal of Education and e-Learning Research Vol. 4, No. 2, 46-62, 2017ISSN(E) 2410-9991 / ISSN(P) 25180169

DOI: 10.20448/journal.509.2017.42.46.62Received: 10 May 2017. Revised: 6 July 2017.Accepted: 7 August 2017.Published: 18 August 2017.Licensed: This work is licensed under a Creative Commons Attribution 3.0 License Publisher: Asian Online Journal Publishing Group.

[80] Hassan M. H. Mustafa et. al. "Application of Artificial Neural Networks Modeling for Evaluation of ELearning/ Training Convergence Time." Paper Published in American Journal of Education and Learning, 2(2): 159-179. Funding: This study received no specific financial support. This work is licensed under a Creative Commons Attribution 3.0 License Competing Interests: History: Received: 7 March 2017/ Revised: 22 September 2017/ Accepted: 4 October 2017. Publisher: Online Science Publishing On 19th October 2017.

[81] Hassan M. H. Mustafa, Satish Gajawada (2018) "Application Of Artificial Neural Networks Modeling For Self-Assessment Performance Evaluation Regarding Blended Learning Paradigm (Brain Based Approach)" Published at American Journal of Engineering Research (AJER) e-ISSN: 2320-0847 p-ISSN : 2320-0936 Volume-7, Issue-8, pp. 200-209 